$\xi=$ 囯

\title{
Determination of orthometric elevations using gnss-derived height with the egm2008 geoid height model
}

\author{
Emmanuel Menegbo * \\ Department of Surveying \& Geo-informatics, Port Harcourt Polytechnic Port Harcourt, Nigeria \\ *Corresponding author E-mail: nenibarini@yahoo.com
}

\begin{abstract}
The Global navigation satellite systems (GNSS) has imparted positively on civilian positioning \& surveying in the horizontal component in Nigeria for the past two decades. The GNSS receivers' data are longitude, latitude \& elevation. However, the vertical distance measurement have not been fully exploited by geodetic and land surveyors. The GNSS derived heights are ellipsoidal elevation. To convert the GNSS elevation to orthometric heights, a geoidal elevation models is needed. The Earth Gravitational Model, 2008 (EGM2008) is a global geoidal models that can be used to obtain GNSS orthometric heights by defining the relationship with the ellipsoid. This work determines GNSS-derived orthometric heights with ellipsoid-geoidal relationship using GPS ellipsoidal heights and EGM2008 geoidal model GIS data. The EGM2008 GIS data was downloaded and interpolated with GPS data to obtain geoidal heights using ArcGIS 10.1. GNSS-derived heights determined with geoid-ellipsoid relationship formula. The result shows minimum elevation of $-2.37599 \mathrm{~m}$ and maximum elevation of $53.8566 \mathrm{~m}$. The derived orthometric heights use to create a model in raster format. The orthometric elevation models created useful in all vertical surveying work, construction work and urban planning. The GNSS orthometric heights models need to be compare with spirit levelling and the local geoidal model determined for improve accuracy.
\end{abstract}

Keywords: EGM2008; Geodetic Heights; GNSS; Orthometric Heights; Vertical Benchmark.

\section{Introduction}

Accurate determination of benchmark heights with respect to the geoid surface from GPS derived heights has dominated geodesist's areas of research currently (Kemboi et al, 2016). Orthometric elevations are used for engineering construction project \& land surveying with referenced geoid surface. The Earth Gravitational Model, 2008 (EGM2008) is one of the current global geoidal model and available in Geographic information systems (GIS) raster format.

The NAVigation System with Time and Ranging (NAVSTAR) Global Positioning System (GPS) one of the Global navigation satellite systems (GNSS) have impacted on traditional horizontal surveying in Nigeria and the world at large. Nigeria has adopted its use for control surveying; also the US National Geodetic Survey (NGS) has adopted GPS technology surveying techniques.

GPS defines any point on the earth surface by longitude, latitude, and elevations (ellipsoidal height).Vertical surveying control in Nigeria remains undeveloped as in the US. Orthometric elevation is conventionally determined by the use of spirit levelling and defined by the vertical distance above the geoids as measured along plumeline.GPS elevations are obtain directly from the geocentre position vector from GPS measurement (sickle,2008). The geoid is an equipotential surface as define by gravity (Ghilani and wolf, 2008). The GPS elevation is measured in relation to the WGS84 ellipsoid and is called geodetic height or ellipsoidal heights (Uzodinma 2015).

GPS elevation can be converted to orthometric heights using geoidal models (Uzodinma 2015). Earth Gravitational Model EGM2008 is a useful model for the above conversion. EGM2008 gravitational model uses spherical harmonic degree and order
2159 (NGA 2013). The WGS 84 constants used to define the reference ellipsoid with EGM2008 are (NGA, 2013);

- $\quad$ semi-major, $\mathrm{a}=6378137.00 \mathrm{~m}$

- $\quad$ flattening, $f=1 / 298.257223563$

- Earth's mass and the Gravitational Constant, $\mathrm{GM}=$ $3.986004418 \times 1014 \mathrm{~m}^{3} \mathrm{~s}^{-2}$

- Earth's angular velocity, $\omega=7292115 \times 10-11$ radians $/ \mathrm{sec}$. Orthometric elevations information is useful in tidal measurement, construction projections, urban planning etc. This work use a created raster geoidal model (EGM2008) of 2.5 x 2.5-minute resolution and GPS controls spread all over Rivers state to determined the orthometric heights model of the study area using geoidellipsoidal relationship and GIS tools.

\section{Study area}

The Rivers state lies at latitudes $4.396420^{\circ} \mathrm{N}$ and $5.982150^{\circ} \mathrm{N}$ and longitudes $6.552790^{\circ} \mathrm{E}$ and $7.658370^{\circ} \mathrm{E}$. rivers state is in the southern part of Nigeria with an area of approximately 278.080276 sq.km base on Spatial query using ArcGIS tool and view from the Rivers state administrative map shows it is bounded in north boundaries with

The population of Rivers State is 5,198,716 (census, 2006). It is today the centre of Oil activities in Rivers State in Nigeria.

Eludoyin et al, (2011) describe Rivers state as a monsoon tropical climate that hot is as a result of its position on equator. A major characteristic of a tropical monsoon climate is rainfall which usually between April \& October with range between 2000 - 2500 $\mathrm{mm}$ it record high humidity with higher inland temperature yearly (Eludoyin et al, 2011). Rivers state upland vegetation is mostly 
palms (raffia), mangrove thick forest with rain light forest (Eludoyin et al, 2011).

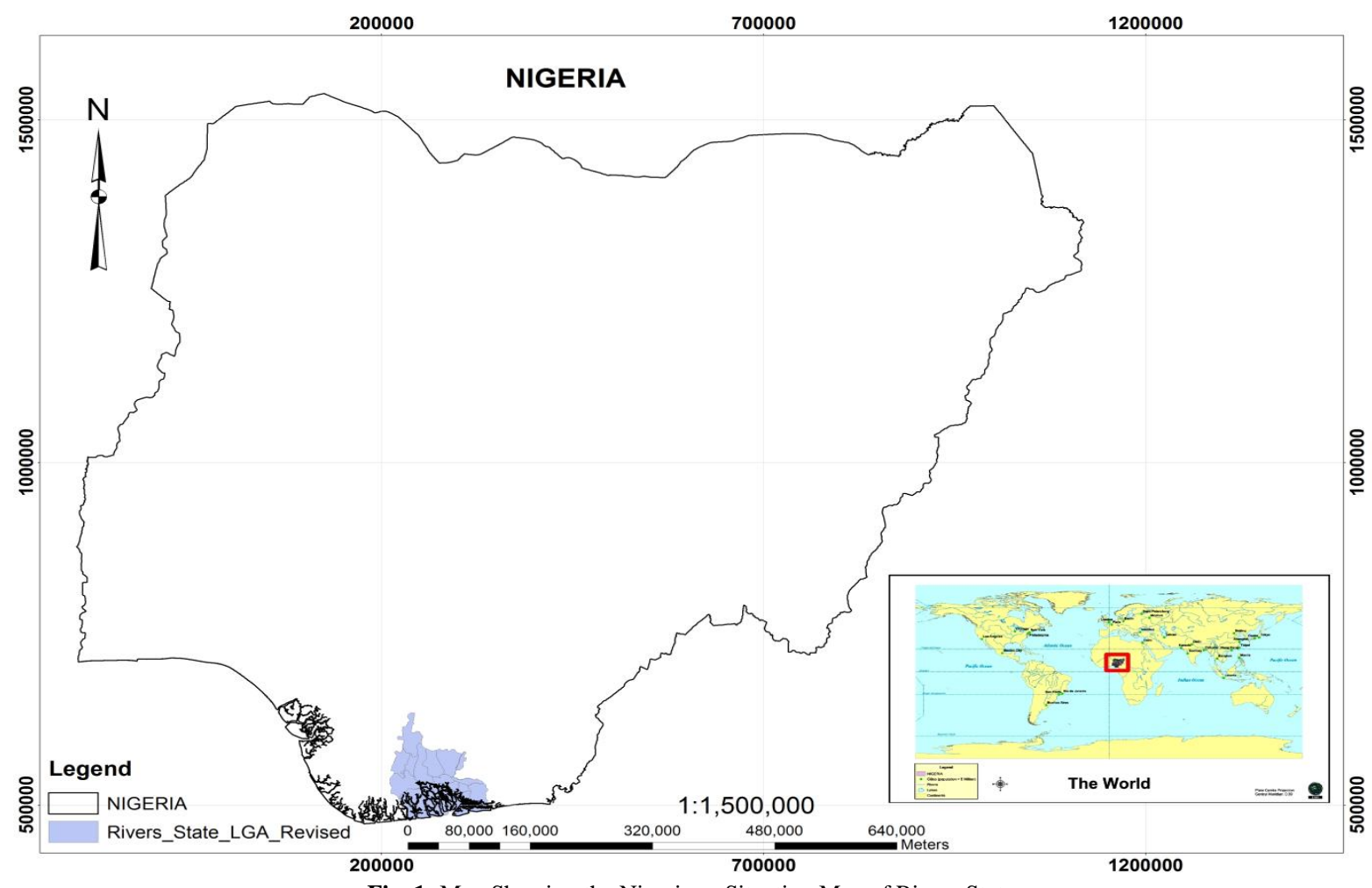

Fig. 1: Map Showing the Nigeria as Situation Map of Rivers State.

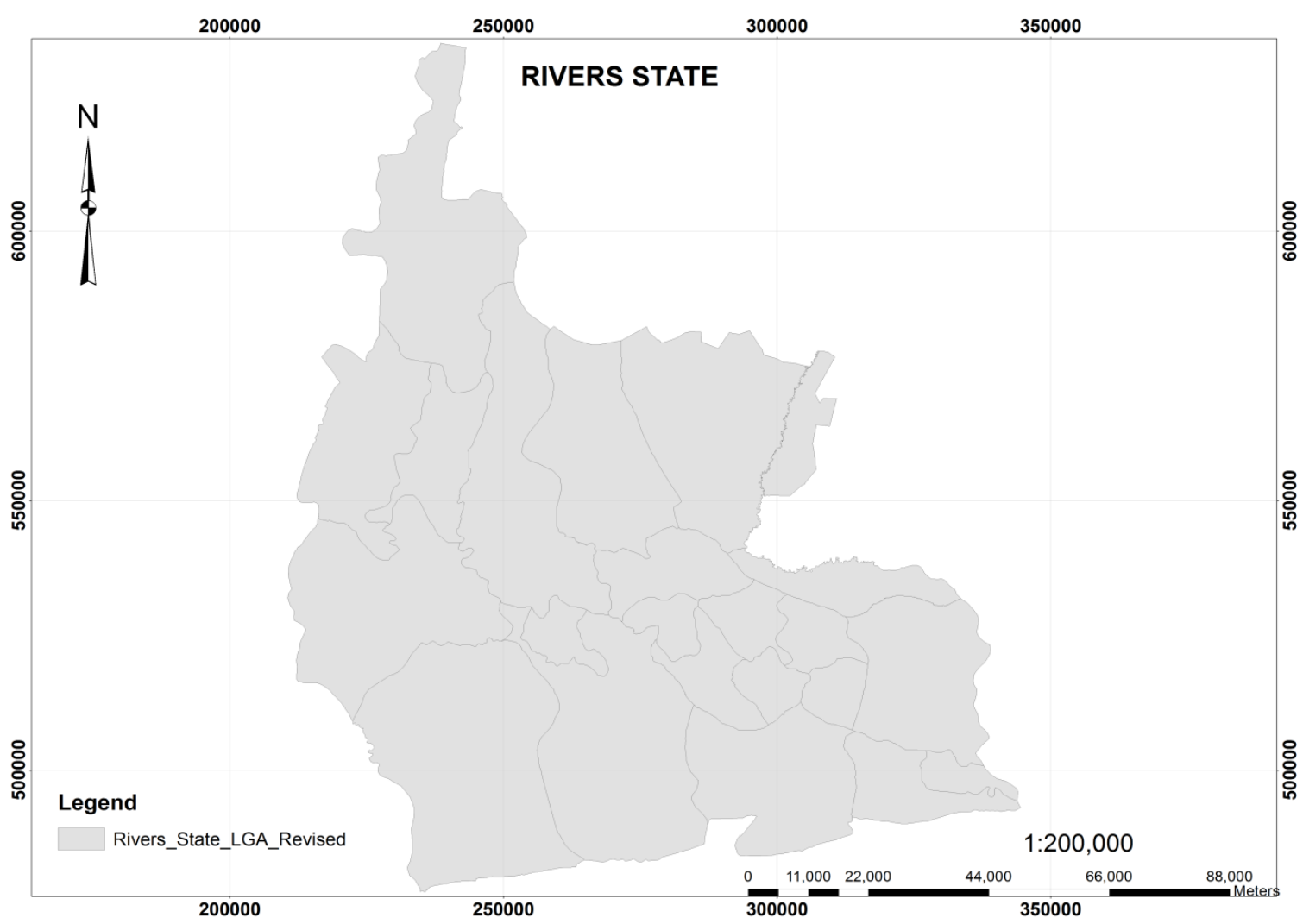

Fig. 2: Map Showing the Study Area Rivers State.

\section{Methodology}

"Geoid is an equipotential gravitational surface located approximately at mean sea level, which is everywhere perpendicular to the direction of gravity"(Ghilani and wolf, 2008).

"Ellipsoid is a mathematical surface obtained by revolving an ellipse about the earth's polar axis" (Ghilani and wolf, 2008)
Orthometric height as defined earlier is the height above the geoid. "Deflection of the vertical is the angle between the direction of a plume line with the ellipsoidal normal through the same point" (Sickle, 2008).

"Mean sea level is the average location of the interface between ocean and atmosphere, over a period of time that all the ramdom and periodic variations of short duration average to zero" (Sickle, 2008) 


\subsection{Height relationships}

The surveyor can only determine the orthometric elevation of a point of a GPS measurement by knowing the extent of the separation between the ellipsoid and geoid. In transforming Gps elevation (ellipsoidal heights) h, into orthometric elevations $\mathrm{H}$, is given as (sickle, 2008);

$$
\mathrm{H}=\mathrm{h}-\mathrm{N}
$$

Where, $\mathrm{N}$ is the geoid-ellipsoidal separation (Geoidal undulation or Geoidal Height).

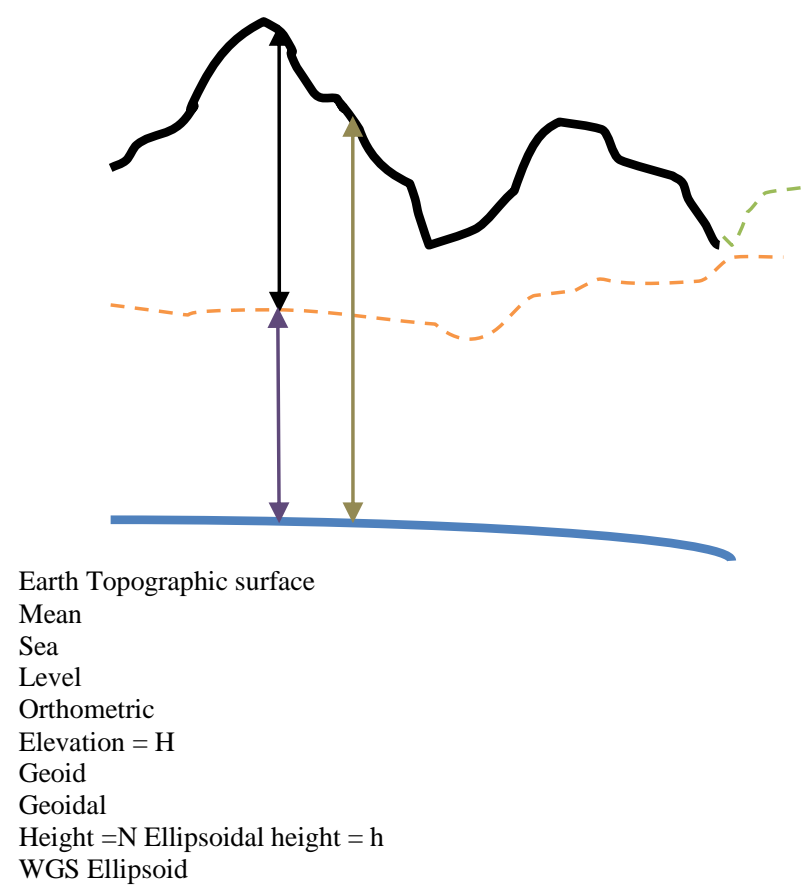

Fig. 3: Relatiotionships betweens Difference Surface.

\subsection{Determination of orthometric heights with GPS derived elevation with EGM2008}

The field observation methods for GPS point positioning make equation (1) to now become;

$\mathrm{H}=\mathrm{h}_{\mathrm{GNSS}}-\mathrm{N}_{\mathrm{EGM} 2008}$

Where;

NEGM2008 = Geoidal Height

hGNSS = Geoidal Height, and

$\mathrm{H}=$ orthometric heights

But in relative GPS positioning, the observation baseline of the components can be calcutated accurately with geodetic difference in height $(\Delta h)$ of the two GPS control points (Idwijay, 2003). From equation point one and two can be rewrite as;

$$
\begin{aligned}
& \mathrm{H}_{1}=\mathrm{h}_{1}-\mathrm{N}_{1} \\
& \mathrm{H}_{2}=\mathrm{h}_{2}-\mathrm{N}_{2}
\end{aligned}
$$

And this no becomes;

$$
\mathrm{H}_{2}-\mathrm{H}_{1}=\Delta \mathrm{H}=\mathrm{h}_{2}-\mathrm{h}_{1}(\Delta \mathrm{h})+\mathrm{N}_{2}-\mathrm{N}_{1}(\Delta \mathrm{N})
$$

Or

$\Delta \mathrm{H}=\Delta \mathrm{h}-\Delta \mathrm{N}$

Rewriting (6) in form of (2) as;

$\Delta \mathrm{H}=\Delta \mathrm{h}_{\mathrm{GNSS}}-\Delta \mathrm{N}_{\mathrm{EGM} 2008}$

In practise, due to varying undulation geoid $(\Delta \mathrm{N})$, a change for geodetic height $(\Delta \mathrm{h})$ will not be equal to a change in the orthometric height $(\Delta \mathrm{H})$. This implies that $\Delta \mathrm{h}$ and $\Delta \mathrm{N}$ determination must be accurate and this work assume that they are correct as possible.

\subsection{Data collection and methods}

The Earth Gravitational Model (EGM2008) was downloaded from http://earth-

ifo.nga.mil/GandG/wgs84/gravitymod/egm2008/egm08_gis.html. The GPS elevation data and administrative boundary data used in this work was collected from the office of the Surveyor-General of Rivers State, Nigeria (OSGRS).

The EGM2008 used as geoidal undulation in this work was masked to the administrative boundary of Rivers State using ArcGIS 10.1. The GPS coordinates was interpolated with EGM2008 dataset in ArcGIS 10.1 to extract geoidal base heights. Determination of orthometric heights was carried out using Microsoft excels. Lastly, the orthometric heights were modelled in form of a raster dataset (digital elevation model, DEM) in ArcGIS 10.1. This method is summarised in figure 4 .

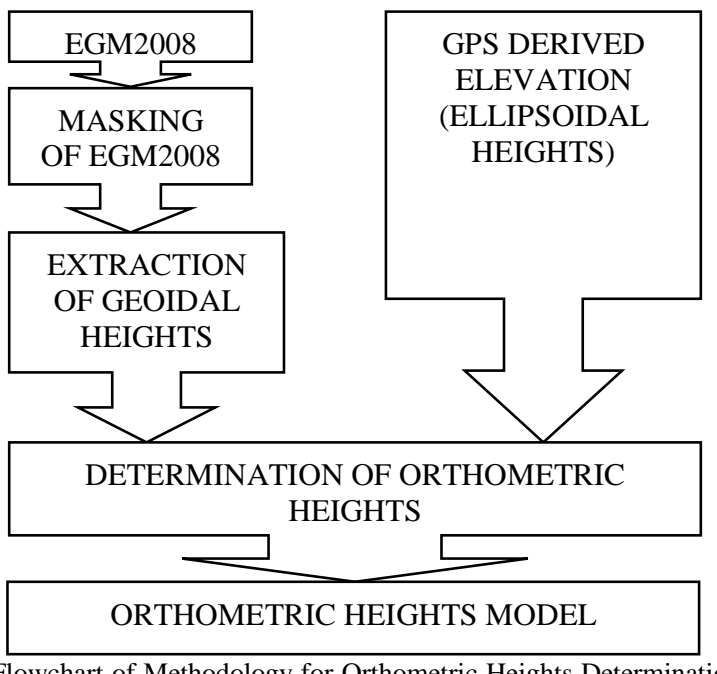

Fig. 4: Flowchart of Methodology for Orthometric Heights Determination with GNSS.

\section{Results and discussion}

Results deduce from equation (1) to determine orthometric heigthts at 50 GPS control stations shows minimum elevation of $2.37599 \mathrm{~m}$ and maximum elevation of $53.8566 \mathrm{~m}$. Orthometric heights were calculated using Earth Gravitational Model, 2008 as geoidal undulation and GPS benchmark as GNSS. The overall results are as shown in table 1 below. 
Table 1: Results of Orthometric Heights Determination with GNSS(50 GPS Control)

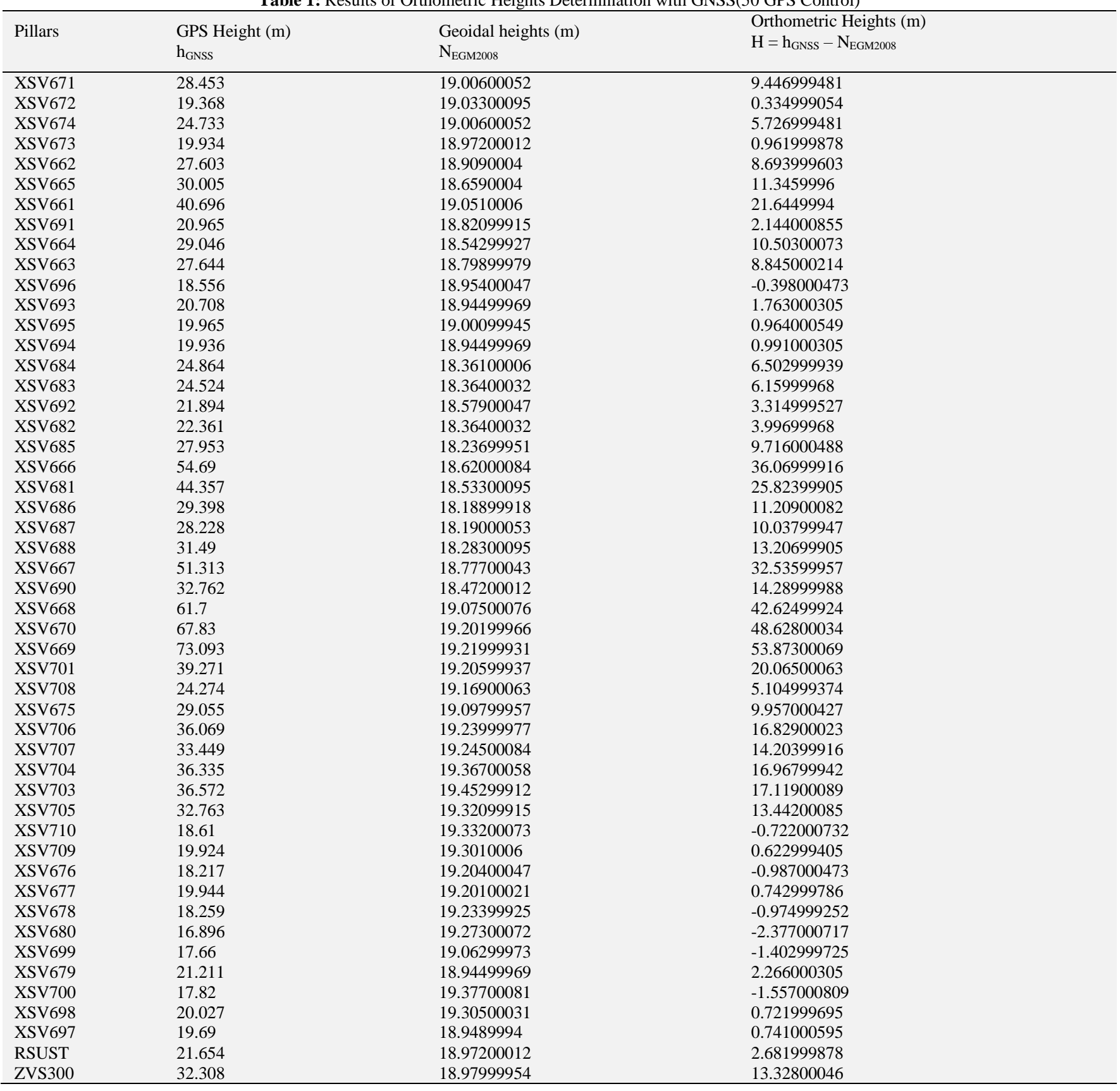

The orthometric heights models in a digital elevation model (DEM) as shown in Figure 6.

The GPS controls distribution density over the study area in figure 5 .

The results were obtained from a mathematical model calculation by combining gravimetric information (data) with distributed network of GNSS control points. Differential correction needed as requirement for surveying $\&$ engineering work accuracy. That is, difference between base station and the rover must be determined as accurate as possible. Guideline of publication NOS NGS-58 should be observed for GNSS field measurement. Geodetic levelling needed in other to compare with GNSS data. 


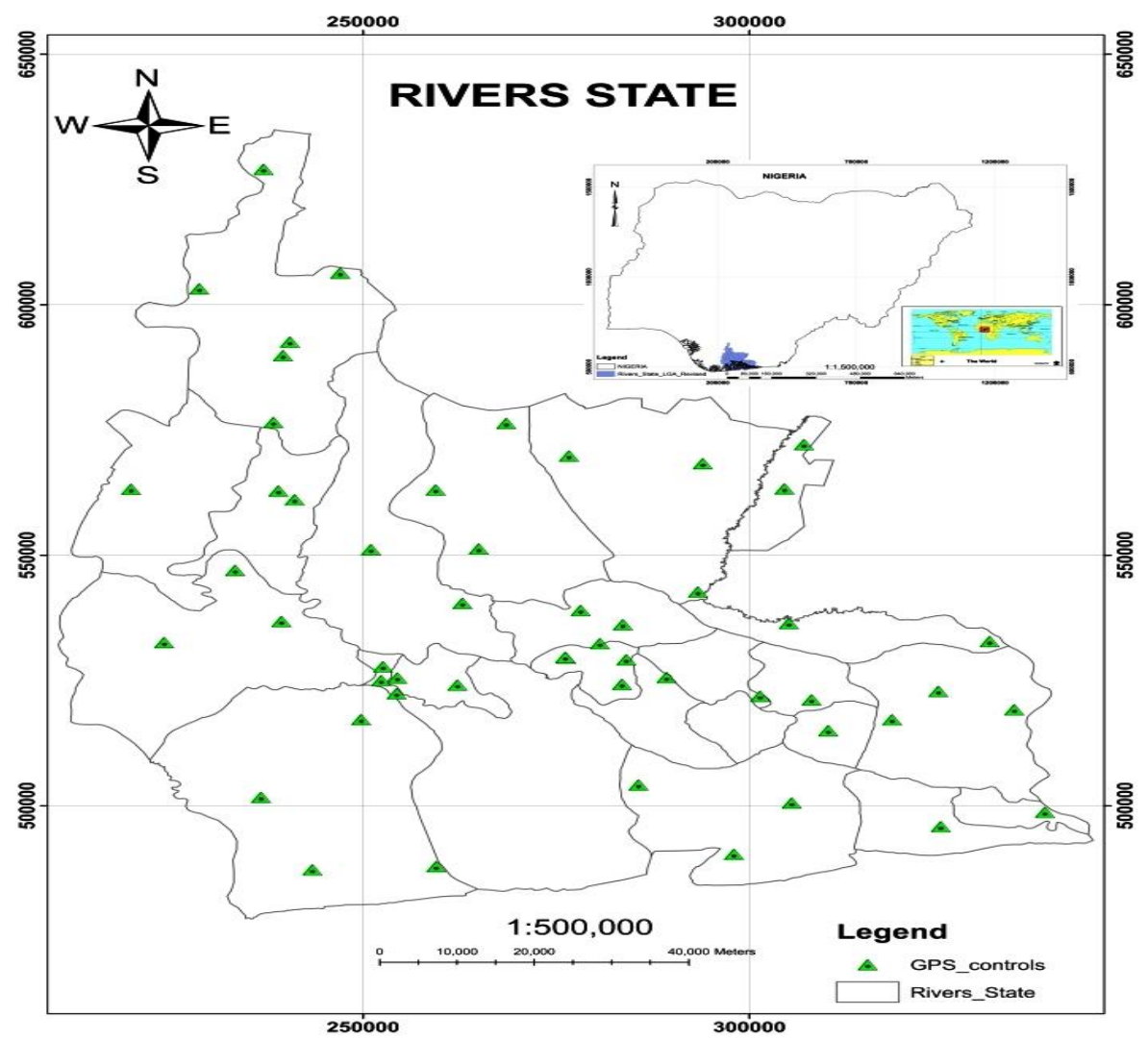

Fig. 5: GPS Controls Distribution Density over the Study Area.



Fig 6: The Orthometric Heights Models. 


\section{Conclusion and outlook}

The result obtain shows that orthometric heights at any point on the earth surface can be estimated using mathematical model. GNSS observations on benchmark and a geoidal heights model such as EGM2008 needed to achieve results. High control density needed for small area to achieve needed accuracy. Ellipsoidal differences in height between benchmark should be determined in Differential GPS to achieved accuracy for surveying and engineering applications.

Future work within the study area includes; validation of EGM 2008 accuracy, differential levelling to compare with GNSS derived heights and determination of a geoidal model.

\section{Acknowledgement}

I thank the formal Surveyor-General of Rivers State, Surveyor Gaius Assor and Surv. Peter Ogolo for the GPS benckmark and the administrative map of Rivers state used for this research.

\section{References}

[1] Eludoyin O.S. Wokocha C.C. and Ayolagha G. (2011). GIS Assessment of Land Use and Land Cover Changes in Obio/Akpor L.G.A., Rivers State, Nigeria. Research Journal of Environmental and Earth Sciences, 3(4), 307-313. Retrieved May 21, 2016, from http://maxwellsci.com/print/rjees/v3-307-313.pdf

[2] Ghilani D.C and Wolf P.R. (2008). Elementary Surveying.An introduction to Geomatics (12 ed.). International: Pearson international Edition.

[3] Idwijay. (2003, 11 03). Elevations (Orthometric Heights) From GPS. Michigan. Retrieved uly 08, 2016, from http://www.tech.mtu.edu/courses/su4100/Course_Material/Elevatio ns\%20from\%20GPS.pdf

[4] Kemboi K. E. and Odera P. A. (2016). Estimation of orthometric height using EGM2008 and GPS over Nairobi County and its environs. Journal of Agriculture, Science and Technology, 17(2), 118 131. Retrieved November 10, 2016, from http://journals.jkuat.ac.ke/index.php/jagst/article/view/1283

[5] NGA. (2013, April 29). EGM2008 - WGS 84 Version. USA. Retrieved June 21, 2016, from http://info.nga.mil/GandG/wgs84/gravitymod/egm2008.html

[6] Sickle J. V. (2008). GPS for Land Surveyors (3 ed.). California: CRC Press.

[7] Uzodinma V. N. (2016). Advanced GPS Satellite Surveying.Lecture note. Nnamdi Azikiwe University, Department of Surveying \& Geoinformatics, Awka. 